\title{
A personalidade feminina e sua dimensão social à luz da psicodrama
}

\author{
The female personality and its social \\ dimension in the light of psychodrama
}

\section{Gilmar Antoniassi Junior ${ }^{1}$ Glória Lúcia Alves Figueiredo 2 (1) Regina Celia de Souza Beretta ${ }^{3}$ (1)}

${ }^{1}$ Autor para correspondência. Faculdade Patos de Minas (Patos de Minas), Universidade de Franca (Franca). Minas Gerais, São Paulo, Brasil. jrantoniassi@hotmail.com

2,3Universidade de Franca (Franca). São Paulo, Brasil. gloria.figueiredo@unifran.edu.br, regina.beretta@unifran.edu.br

\begin{abstract}
RESUMO | OBJETIVOS: Compreender os aspectos da personalidade feminina e sua influência no ambiente, em sua dimensão social à luz psicodrama. METODOLOGIA: Trata-se de uma pesquisa intervencionista, do tipo transversal, de caráter qualitativo, cujo objetivo é estudar os aspectos da personalidade feminina e sua influência no ambiente em sua dimensão social, à luz do psicodrama. O estudo foi realizado com um grupo de mulheres de uma cidade do interior do estado de Minas Gerais; teve a participação de 18 mulheres universitárias. Sendo realizado um encontro psicodramático, denominado o encontro do EU. Na ocasião foi aplicado o Z-Teste a Técnica de Zulliger. RESULTADOS: Evidenciaram-se de modo geral que as participantes apresentaram fatores resolutos em relação aos diferentes aspectos da estrutura da personalidade, relativos à organização e ao funcionamento da personalidade. CONCLUSÃo: Conclui-se que a espontaneidade e a capacidade de ajustamento ao ambiente humano, em relação aos aspectos nominados relacionamentos interpessoais indicam baixa capacidade de interação social, com dificuldade de interagir no ambiente.
\end{abstract}

PALAVRAS-ChAVE: Feminino. Psicodrama. Personalidade. Ambiente. Apoio Social.

\begin{abstract}
OBJECTIVES: Understand aspects of personality and its influence on the environment, in its social dimension in the light of psychodrama. METHODOLOGY: This is a research, interventionist, transversal, of qualitative character, whose objective is to study the aspects of the female personality and its influence on the environment in its social dimension, in the light of psychodrama. The study was carried out with a group of women from a city in the interior of the state of Minas Gerais, Brazil; 18 university women participated. Being held a psychodramatic meeting, called the meeting of the EU. At the time, the Z-Test Zulliger. RESULTS: It was evidenced in general that the participants presented resolute factors in relation to the different aspects of the personality structure, related to the organization and functioning of the personality. CONCLUSION: It is concluded that spontaneity and the ability to adjust to the human environment, in relation to the aspects called interpersonal relationships, indicate low capacity for social interaction, with difficulty in interacting in the environment.
\end{abstract}

KEYWORDS: Feminine. Psychodrama. Personality. Environment. Social support. 


\section{Introdução}

No decorrer de muitas décadas, as mulheres vêm lutando para conquistar o seu espaço em uma sociedade patriarcal e machista, denunciando as diversas desigualdades existentes entre homens e mulheres, buscando para si direitos igualitários. Aos poucos foram acontecendo importantes transformações em relação ao ingresso das mulheres no mercado de trabalho, em áreas consideradas de domínio dos homens. Um caminho considerado longo e árduo (Alves, 2017; Weber, 1964).

Dentre diversas mudanças no cenário mundial, a participação feminina segue cada vez mais expressiva no mercado de trabalho remunerado, e em muitas situações chega a ser o principal suporte financeiro familiar. Isso significa que além da maternidade, a mulher passa a preocupar-se com a sua satisfação pessoal e com o sucesso de sua carreira profissional. Mas nem sempre foi assim. Em tempos passados, a sociedade acreditava que o homem era o único provedor da família e que a mulher ficava responsável pela educação dos filhos e pelo lar; sequer podia pensar em ganhar dinheiro (Simões \& Hashimoto, 2012).

À medida que o tempo foi passando, as mulheres foram conseguindo vencer as barreiras do papel que Ihes era imposto, ou seja, de serem apenas esposas, mães, filhas e donas do lar. Isso tudo foi ficando no passado, sendo possível perceber que a partir da década de 70 as mulheres começaram a conquistar melhores lugares de destaque, dentre estes, por exemplo, na política. A partir da década de 70 e 80 , o movimento anteriormente chamado de "feminismo" passa então a se chamar "feminista". Assim as muIheres passaram a serem vistas (pelos homens) como mulheres capazes, que com muita força e coragem começam suas vidas fora do lar, realizando os trabaIhos que por muito tempo eram de seus pais e maridos (Schlickmann \& Pizarro, 2013).

A partir do século XX a mulher viu-se obrigada a trabalhar para sustentar sua família. Desde então se dedicou a mostrar suas competências e habilidades no mercado de trabalho. Até hoje as mulheres enfrentam dificuldades, pois são mães, esposas e muitas vezes mantenedoras do lar. Destacam-se por não deixarem a desejar nas suas atividades, buscando sempre o aperfeiçoamento. Essas mulheres vivem sempre um dilema: conciliar o cuidado com os filhos, a profissão e as tarefas domésticas (Querino et al., 2013).
Em alguns setores, a participação da mulher no mercado de trabalho tem tido grandes saltos (Souza \& Santos, 2014). Em um histórico de dominação feminina, a mulher, mesmo no séc. XXI, vem sendo dominada, mas hoje não pelos maridos e sim pela sociedade, que faz com que a mulher assuma vários papéis como ser trabalhadora, 'dona de casa', mãe. Ao final da jornada de trabalho, estas chegam às suas casas e precisam encarar os afazeres domésticos. Além disso, têm culturalmente a "obrigação" de cuidar dos fiIhos (Back et al., 2012).

Em um cenário de grandes avanços tecnológicos abriu-se espaço para uma maior participação feminina no mercado de trabalho, não apenas pela necessidade de complementar a renda em casa, mas também pela quebra de padrões de comportamentos que, através dessas mudanças, fizeram-se necessários. Além disso, o mercado flexível vê a necessidade de habilidades como capacidade criadora, docilidade, empatia para lidar com o cliente e "jogo de cintura", que são características consideradas femininas. Hoje, a presença cada vez mais expressiva das mulheres em cargos e funções mais diversificadas mostra que elas vêm impondo-se nos diversos ambientes de produção social (Amaral, 2012).

Com isso, pode-se confirmar que todo discurso e construção social embasadas na fragilidade feminina encontram-se equivocadas, levando em consideração a necessidade de esforço físico nos trabalhos domésticos que anteriormente eram apenas realizados pelas mulheres. E quando essas mulheres buscam espaço nesses trabalhos que são considerados masculinizados, pode-se perceber que elas testam mais uma vez a regra da fragilidade. Assim, a dificuldade de a mulher destacar-se em um ambiente masculino de trabalho implica em ser agravada, de maneira especial, pela condição de disparidade que é cominada desde o princípio. A simples imersão da mulher em um universo masculino já indica que as modificações nesse espaço podem, aos poucos, virem a ocorrer (Salvani et al., 2017).

O processo de reconhecimento social do papel das mulheres foi sendo alterado no decorrer do tempo. A relação de parceria entre homens e mulheres, que já existia em determinadas épocas, aos poucos se transformou em desigualdade e opressão. Elas, que eram encarregadas dos trabalhos domésticos, cuidados da casa, das crianças e em servirem os maridos, agora, com a sua efetividade no mercado de trabalho 
somada às suas diferentes responsabilidades domésticas acaba gerando um conflito de identidades e uma sobrecarga. Nesse caso, as mulheres reconhecem sua identidade de opressão, exploração e submissão, mas o que se busca é a desconstrução desse pensamento e o reconhecimento respeitoso de uma nova identidade social (Maders \& Angelin, 2012), primeiramente em si mesma.

Na presente pesquisa utilizou-se como método de investigação e intervenção o psicodrama por meio do jogo psicodramático; ao qual trabalha as relações interpessoais, as ideologias sejam elas particulares e coletivas por intermédio da representação criativa e espontânea do sujeito (Antoniassi Junior et al., 2018). No jogo psicodramático utiliza-se de uma proposta de atividade pautada em uma ação, um ato de movimentar-se pelo o uso do recurso interno da espontaneidade criatividade, onde o participante irá criar aquilo que deseja, permitindo aos envolvidos ter acesso a uma realidade suplementar implicada em trabalhar com o imaginário (Ramalho, 2010).

O movimento psicodramático se sistematiza a partir dos aspectos da socionomia, sociometria, sociodinâmica e ações sociatria, ou seja, movimentos que envolvem as leis sociais que conduzem o comportamento interpessoal sustentado pelas observações dos modos como as pessoas se interagem a partir da dinâmica do grupo e suas conexões com diferentes contextos; associado à metodologia da representação teatral ao qual Moreno explora a verdade por meio das dramatizações a partir dos papéis que são desempenhados na sociedade (Antoniassi Junior et al. 2018).

No psicodrama a dramatização é o ponto vital que possibilita as reflexões e tomadas de insights, sucedida em meio as etapas de implementação da sessão psicodramática em que se divide em três etapas definidas em aquecimento, dramatização e compartiIhamento; com finalidades específicas de preparar o grupo para ação dramática (aquecimento) constituir a cena (dramatização) e dialogar os impressão e reflexões acerca da cena e as provocações elucidadas (compartilhamento) (Antoniassi Junior et al., 2018; Gambim et al., 2020).

Daí a questão norteadora deste estudo é se haveria a possibilidade de promover nas mulheres a autopercepção de suas características pessoais por meio do psicodrama, no reconhecimento do seu eu?
Segundo Fonseca (2012), o psicodrama traz, nos seus escritos sobre a Teoria da Espontaneidade a matriz de identidade, que é uma rede relacional primária do sujeito desde a infância, que interage com os processos psicológicos, biológicos e socioculturais; essas contribuições morenianas delineiam um esboço de uma teoria da personalidade. Nesse sentido, apresenta-se como objetivo desse artigo compreender os aspectos da personalidade feminina e sua influência no ambiente, em sua dimensão social à luz psicodrama.

\section{Materiais e Métodos}

Trata-se de uma pesquisa de natureza qualitativa e intervencionista, do tipo transversal, de caráter qualitativo, que se apreendeu aos aspectos da personalidade de mulheres, participantes de um grupo de psicoterapia psicodramático; de uma cidade do interior do estado de Minas Gerais. A pesquisa obteve aprovação do Comitê de Ética em Pesquisa (CAAE: CAAE:96025118.2.0000.5495).

A seleção amostral ocorreu por conveniência, de forma intencional, uma vez que as amostras por conveniência não exigem tanto critério na pré-seleção do público a ser pesquisado, ou seja, o universo da pesquisa não precisa estar totalmente definido para que essa seja efetuada. E a amostragem foi intencional justamente por ser um método cuja seleção é baseada no conhecimento sobre a população e o propósito do estudo (Creswell, 2014), em que a circunstância dessa pesquisa trata-se de mulheres no contexto da cidade.

Para acessar essas mulheres, foi constituído um grupo de trabalho com estagiários do curso de Psicologia, capacitados na modalidade do psicodrama, que percorreram programas de rádio, televisão local, afixaram cartazes no centro da cidade e corredores da universidade. O conteúdo dos cartazes era: Psicodrama Público - venha expressar suas emoções. Informava data, horário e local; a fim de convida-las a participarem de um encontro psicodramático.

Foram inclusas como parte do estudo aquelas mulheres maiores de 18 anos, sem limites de idade e ocupação, residentes na cidade; resultando na participação de 18 mulheres. Inicialmente foi explicada a proposta e finalidade da pesquisa e solicitado que assinassem o Termo de Consentimento Livre Esclarecido (TCLE). 
No grupo de psicodrama o encontro é iniciado com uma proposta de uma atividade de aquecimento. O encontro teve duração de quatro horas a sessão e foi denominado de encontro do EU. É importante expor que a sessão psicodramática caracteriza-se por eventos que se abrem e se fecham no mesmo encontro, sendo constituída por três etapas: aquecimento (inespecífico e específico), dramatização e criação, compartilhamento e comentários (Comparini et al., 2015).

Dado isso, como atividade de aquecimento foi proposta uma música, a fim de estabelecer o rapport e criar uma ligação de sintonia e empatia no grupo, por meio do movimento corporal. Para a atividade de dramatização e criação, foi aplicado o Z-Teste a Técnica de Zulliger, em que foram respeitadas as normas de padronização propostas por Vaz e Alchieri (2016) para aplicação coletiva, consistindo-se em dois momentos: o primeiro, denominado associação livre, e o segundo, denominado inquérito.

$\mathrm{Na}$ associação livre, o sujeito deve ser totalmente livre para dar as respostas mais espontâneas possíveis. Já na fase de inquérito, o aplicador teve uma participação fundamental, pois formulou indagações que thes permitiram codificar de maneira adequada as respostas e, depois, analisar os resultados e chegar às conclusões diagnósticas. No primeiro momento, ao entregar a prancha, apenas indagou-se: Com que isso se parece? E assim sucessivamente.

No segundo momento, as figuras foram revistas, repetindo as respostas das participantes, indagando a relação que as mesmas perceberam em cada figura e o porquê. As indagações foram sendo realizadas em cada prancha, marcando a área visualizada pela participante, de acordo com as suas respostas. Por fim, foi aberto espaço ao diálogo para expressão de sentimentos e emoções vivenciados na roda do dia. Cabe aqui um importante parêntese: nota-se que foram dez encontros, com resultados e atividades diferentes.

Nesse artigo, optou-se ao alcance dos resultados obtidos com a aplicação do Z-Teste a Técnica de Zulliger. Trata-se de um instrumento que tem como base o Método de Rorschach e permite, de modo indireto, obter informações sobre o funcionamento psíquico de cada indivíduo ao responder com o que as manchas de tinta parecem-se ou que poderiam ser.
O teste é útil como medida, sobre vários aspectos da personalidade, pois se enquadra na categoria dos métodos de autoexpressão, apoiado em um complexo sistema de análise de respostas, envolvendo tanto os conceitos psicométricos quanto os de projeção (Vaz \& Alchieri, 2016; Villemor-Amaral \& Primi, 2012).

Para as análises dos dados coletados em relação ao Z-Teste a Técnica de Zulliger, seguiu-se a orientação de Vaz e Alchieri (2016), que possui vários sistemas de classificação, nos quais cada resposta é classificada quanto à Localização, aos Determinantes do conteúdo, aos Fenômenos especiais e às Verbalizações mais difíceis. Esses sistemas estão divididos entre dados quantitativos e as análises de Fenômenos especiais, por meio dos quais se tem uma compreensão dinâmica da personalidade. Há três grandes categorias de classificação das respostas, a partir das manchas que estão em cada cartão, dentre elas, os aspectos Globais, os Detalhes comuns, as Respostas de detaIhe incomum, as Subcategorias e o Detalhe diminuto, interno e externo.

Visto que não existe uma lógica de como as coisas acontecem na sessão de psicodrama, é permitido experienciar o momento do aqui e agora. Em virtude dos movimentos provocados pelas ações do jogo psicodramático, os quais serviram de estímulo à espontaneidade e à criatividade, isso se torna um instrumento de ação eficaz, porquanto proporciona a expressividade da afetividade, sinalizando a possibilidade de haver uma transposição das conservas culturais, que criam certa resposta original, tornando-a primordial à existência saudável (Comparini et al., 2015). Por essa razão, utilizou-se tratamento da abordagem qualitativa para interpretação e análise das informações, levando-se em conta o uso da Análise da Conversação e da Fala (Bauer; Gaskell, 2015; Gomes, 2014; Myers, 2015)

\section{Resultados e Discussão}

Participaram do encontro 18 mulheres com idade variada entre 21 a 50 anos, sendo 13 participantes com idade na faixa etária de 20 a 27 anos, seguido de 3 mulheres entre 30 a 37 anos e uma mulher com 41 anos e outra com 50 anos; uma parcela das universitárias eram mães e a maioria solteiras. 
No que se refere aos fatores da personalidade, evidenciou-se de modo geral que as participantes apresentaram elementos resolutos em relação aos aspectos estrutura da personalidade, relativa à organização e ao funcionamento da personalidade, conforme tabela 1.

Tabela 1. Distribuição dos resultados em relação aos diferentes aspectos das características da personalidade das mulheres participantes do grupo psicodramático. Patos de Minas, 2020

\begin{tabular}{|c|c|c|c|c|}
\hline Aspectos & Inferior & Médio & Superior & Resultado \\
\hline $\begin{array}{l}\text { Capacidade de desempenho e de adaptação } \\
\text { Geral }\end{array}$ & 1 & 15 & 2 & Média \\
\hline $\begin{array}{l}\text { Controle geral (dimensão racional), expressão } \\
\text { lógica do processo perceptivo }\end{array}$ & 2 & 12 & 4 & Média \\
\hline $\begin{array}{l}\text { Capacidade para estabelecer diferenciação } \\
\text { perceptiva, raciocínio lógico }\end{array}$ & 5 & 9 & 0 & Média \\
\hline Espontaneidade, criatividade, empatia & 2 & 10 & 6 & Média \\
\hline Impulsividade e dinamismo & 9 & 6 & 3 & Inferior \\
\hline Relacionamento interpessoal & 9 & 3 & 6 & Inferior \\
\hline Tendência à excitabilidade emocional & 18 & 0 & 0 & Inferior \\
\hline Ansiedade e adaptação afetiva & 17 & 1 & 0 & Inferior \\
\hline Ansiedade situacional e precário controle & 18 & 0 & 0 & Inferior \\
\hline Traços depressivos de personalidade & 13 & 4 & 1 & Inferior \\
\hline Interação social & 18 & 0 & 0 & Inferior \\
\hline Tendência à reação emocional intensa & 17 & 1 & 0 & Inferior \\
\hline $\begin{array}{l}\text { As pessoas (o ser humano) na percepção do } \\
\text { examinando }\end{array}$ & 4 & 6 & 8 & Superior \\
\hline Percepções infantis, também sadias no adulto & 3 & 5 & 10 & Superior \\
\hline Percepção de conjunto e capacidade de síntese & 1 & 12 & 5 & Média \\
\hline Objetividade & 4 & 14 & 0 & Média \\
\hline Percepção de detalhe & 8 & 3 & 7 & Inferior \\
\hline
\end{tabular}

As análises do material coletado de modo geral apontam adequada capacidade de desempenho, de produção, de realização e de adaptação à tarefa, assim como a capacidade de controle geral sobre seus dinamismos psicológicos; há adequada capacidade de controle de atitudes e reações comportamentais. Indicam ainda potencial intelectivo, racional e lógico adequados para captação, percepção e integração das coisas. Adequados ao funcionamento do pensamento para perceber e se expressar com clareza, precisão, coerência e objetividade.

A capacidade de controle de atitudes é influenciada por uma combinação de traços de personalidade. Níveis mais altos dela são associados a inúmeros benefícios, inclusive relacionados ao alto desempenho e produção, seja de qualquer atividade exercida no ambiente (Lacaille et al., 2013).

As mulheres mostraram um bom nível de autocontrole psicológico que, de acordo com Caprini e Motta (2020), é o nome que dá ao conjunto de competências relacionadas a lidar com emoções. Mais especificamente, como e quanto se percebe, processa, compreende e tem habilidade de gerenciá-las (Caprini \& Motta, 2020). 
O teste revela dados de espontaneidade e capacidade de ajustamento ao ambiente humano, que são expressões de imaginação criadora e da empatia, como condição de relacionamento humano. Uma vez que para Antoniassi Junior et al. (2020) o psicodrama a espontaneidade desempenha uma função de componente essencial da criatividade para conviver nos diferentes espaços e desempenhando os diferentes papéis.

Logo, a empatia é um conceito amplo que se refere às reações cognitivas e emocionais de um indivíduo às experiências observadas de outro. Ter empatia aumenta a probabilidade de ajudar os outros e mostrar compaixão, além dela ser alicerce da moralidade (Bucci, 2020).

Também existe um componente biológico em torno dos aspectos da personalidade. Segundo Tao (2016), há evidências preliminares de neurônios-espelho que disparam quando os humanos observam e experimentam emoções. Existem também partes do cérebro no córtex pré-frontal medial que mostram sobreposição de ativação para pensamentos e julgamentos focados em si mesmos e nos outros.

No tocante aos aspectos de iniciativa e capacidade para competição, os dados encontram-se abaixo da média esperada, podendo indicar certa acomodação e dependência, sendo indicativo, ainda, de não se ter senso de iniciativa e de competição. E em relação aos aspectos nominados relacionamento interpessoal, os resultados apresentam-se abaixo da média esperada, indicando baixa capacidade de interação social. Portanto, demonstra uma dificuldade de interação com o ambiente e em se posicionar entre os pares, com baixa capacidade de estabelecer contato humano e de interação social.

Os relacionamentos interpessoais envolvem associações sociais, conexões e/ou afiliações entre diferentes pessoas; tais relações variam no grau de intimidade e/ou autorrevelação, mas também na duração, na reciprocidade e na distribuição de poder. Expressamente observados nas intervenções psicodramáticas devido ao psicodrama ser um método que movimenta as relações interpessoais por meio da interação grupal promovido pelo jogo do improviso por intermédio de iniciativas próprias e internas (Gasques et al., 2019).
O senso de iniciativa refere-se à capacidade de um indivíduo de transformar ideias em ações. Envolve criatividade, inovação e assunção de riscos, bem como a capacidade de planejar e gerenciar projetos para atingir os objetivos. Isso ajuda os indivíduos, não apenas em sua vida cotidiana em casa e na sociedade, mas também no local de trabalho, induzindo-os a terem consciência do contexto de seu trabalho e a serem capazes de aproveitarem as oportunidades. É uma base para habilidades e conhecimentos mais específicos, necessários para aqueles que estabelecem ou contribuem para atividades sociais ou comerciais. Isso deve incluir a consciência dos valores éticos e promover a boa governança. A falta de iniciativa que é gerada pela acomodação, no entanto, pode levar o sujeito a ter dificuldades de interações, automaticamente anulando-se perante os seus pares, optando por um comodismo social (Davel et al., 2020).

Já no tocante às emoções, os dados indicam que as participantes apresentam certo controle, com capacidade de adaptação afetiva, ansiosa e cautelosa no enfrentamento do sofrimento e no evitar pressão, apresentando capacidade para suportar o mínimo de intensidade de um estímulo ansiogênico. Demonstra baixa capacidade para projetar suas reações emocionais. Entretanto, o teste aponta que as participantes não possuem traços depressivos de personalidade, estando abaixo da média.

O controle emocional pode ser pensado como uma faceta da regulação da emoção, mas refere-se principalmente às tentativas de um indivíduo de gerenciar a geração, experiência ou expressão da emoção e / ou suas respostas emocionais. Assim como a expressão emocional, ele está vinculado ao contexto mais amplo da regulação da emoção. O controle emocional pode ocorrer como parte da regulação focada no antecedente antes da geração da emoção ou por meio da regulação focada na resposta, depois que uma emoção foi gerada. E pode referir-se à capacidade de exercer influência sobre a emoção e modular essa emoção por meio do uso de estratégias cognitivas ou comportamentais. As maneiras pelas quais os indivíduos são capazes de alcançar o controle emocional têm implicações para a saúde e o bem-estar (LaCaille et al., 2013). 
No psicodrama as emoções são organizadas através da improvisação das possibilidades de vivenciar uma ação real ou simbólica, implicando diretamente na elaboração do seu eu interior servido do reconhecimento de capacidade espontânea e criativa de conectar no ambiente a diferentes modos, ou seja, reconhecer suas características personificadas e adaptadas a sua realidade momentânea (Antoniassi Junior et al., 2020; Gasques et al., 2019).

Embora o estereótipo seja que os homens têm mais dificuldade de projetar suas reações emocionais, todas as pessoas, em um momento ou outro da vida, podem achar difícil dizer como se sentem. Algumas pessoas desenvolvem uma necessidade excessiva de agradar os outros e de corresponder ao que considera serem as suas expectativas. 0 medo de que as pessoas não gostem delas anula-as de expressarem seus pensamentos e sentimentos (Gutiérrez-Torres \& Buitrago-Velandia, 2019).

Em relação ao conteúdo humano apresentam-se abaixo da média, ou seja, há certa dificuldade em relação à percepção das pessoas, demonstrando indicativo de pouca flexibilidade no processo de adaptação; porém, as participantes expressam capacidade média de síntese e abstração, sendo possível identificar boa capacidade de discernimento e senso de objetividade entre as participantes, percebendo as coisas, os objetos e as pessoas como realmente são na realidade, uma percepção da realidade objetiva. Porém, elas apresentam baixo senso de observação e de serem pouco minuciosas e cuidadosas com as pequenas coisas.

Adaptar significa ajustar-se às novas condições. Porém, para muitos, experimentar algumas mudanças na vida podem ser estressantes. As mudanças emocionais podem ser as mais difíceis de se ajustarem, já que as mesmas requerem um nível mais profundo de adaptação e de movimentação perante o novo (Caprini \& Motta, 2021).

Como o psiquiatra e sobrevivente do Holocausto Victor Frankl apontou em seu livro Man's Search for Meaning, há eventos que acontecem que estão além do nosso controle, e então há nossa atitude em relação ao que acontece, sobre a qual temos mais controle (Frankl, 2006).
Em sua definição mais simples, o discernimento nada mais é do que a capacidade de decidir entre a verdade e o erro, o certo e o errado. O discernimento é o processo de fazer distinções cuidadosas nos pensamentos sobre a verdade. As pessoas que apresentam tal habilidade possuem maior percepção do mundo, sabendo separar aquilo que lhes fazem bem ou não. Entretanto, a falta de discernimento leva ao engano; indivíduos com pouco discernimento tendem a serem enganados em suas relações sociais e até usados por outros.

\section{Conclusão}

Através da avaliação dos aspectos da personalidade feminina e sua influência no ambiente, em sua dimensão social, foi possível constatar que as mulheres mostram capacidade adequada de desempenho, de produção, de realização e de adaptação à tarefa, assim como a capacidade de controle geral, destacando um nível de autocontrole psicológico, o qual é responsável pela percepção, pelo processamento, compreensão e habilidade gerencial.

Outro fator importante é a capacidade de ajustamento ao ambiente humano, o que aumenta a probabilidade de ajudar os outros e mostrarem compaixão, sendo um facilitador para a convivência humana em todas as suas dimensões sociais. Entretanto essas mulheres despontaram para uma baixa média nos aspectos de iniciativa e capacidade para competição, e a falta desse fator pode levar o sujeito a ter dificuldades de interações, anulando-se perante aos outros optando assim por um comodismo social.

Já no tocante às emoções, os dados indicam que as participantes apresentam certo controle emocional que pode referir-se à capacidade de exercer influência sobre a emoção e modular essa emoção por meio do uso de estratégias cognitivas ou comportamentais. Porém mostraram pouca flexibilidade no processo de adaptação, onde certas mudanças podem ser estressantes, principalmente as emocionais. 
As mulheres estudadas desempenham diversos papéis sociais, como mães, estudantes, esposas e tantas outras. Porém, elas demonstraram se auto anularem perante os seus pares, às vezes deixando suas ideias e percepções guardadas, com medo de desagradar, talvez pelo próprio machismo estrutural que ainda vigora em nossa sociedade.

É importante destacar que umas das limitações do estudo o número de pessoas participantes do grupo embora tenha sido considerado satisfatório pelas apreciações acerca da temática investigada é válido ressaltar que este não possibilita a generalizações no tocante aos aspectos da personalidade feminina e o ambiente. Neste sentido este estudo abre possibilidades para novas pesquisas, que poderiam ampliar a amostra tanto em termos de classe social, cidades representativas, sugere-se que este estudo seja reaplicado com utilização de uma amostra probabilística que possibilite a generalização dos resultados, podendo explorar o lugar que as mulheres ocupam nos diferentes ambientes em que se fazem presente.

\section{Contribuições dos autores}

Antoniassi Junior $G$ participou da concepção, delineamento, busca e análise dos dados da pesquisa, interpretação dos resultados, redação do artigo científico. Figueiredo GLA auxiliou na interpretação dos resultados, redação e da revisão do artigo científico. Beretta RCS participou da redação e revisão final do artigo científico.

\section{Conflitos de interesses}

Nenhum conflito financeiro, legal ou político envolvendo terceiros (governo, empresas e fundações privadas, etc.) foi declarado para nenhum aspecto do trabalho submetido (incluindo, mas não se limitando a subvenções e financiamentos, participação em conselho consultivo, desenho de estudo, preparação de manuscrito, análise estatística, etc.).

\section{Referências}

Alves, D. M. (2017). A mulher na ciência: desafios e perspectivas. Criar Educação, Criciúma, 6(2),1-25. http://dx.doi. org/10.18616/ce.v6i2.3232

Antoniassi Junior, G., Beretta, R., \& Figueiredo, G. (2020). Psicodrama público como método de abordagem no contexto das subjetividades. Id On Line Revista Multidisciplinar e de Psicologia, 14(51),745-753. https://doi. org/10.14295/idonline.v14i51.2626

Antoniassi Junior, G., Gomes, G. A., Beretta, R. C. S., \& Figueiredo, G. L. A. (2018). Psicodrama na promoção da saúde e do bem-estar: experiência de grupo com pacientes oncológicos. Revista Brasileira de Psicodrama, 26(2), 133-139. http://pepsic.bvsalud.org/scielo.php?script=sci_ abstract\&pid=S0104-53932018000200014\&lng=pt\&nrm= iso

Amaral, G. A. (2012). Os desafios da inserção da mulher no mercado de trabalho. Itinerarius Reflectionis, 8(2), 1-20. https://doi.org/10.5216/rir.v2i13.22336

Back, C., Barbosa, J. V., Quevedo, L. K. H., \& Alexandre, I. J. (2012). O papel das mulheres na sociedade: diferentes formas de submissão. Eventos Pedagógicos, 3(2), 328-336. http:// sinop.unemat.br/projetos/revista/index.php/eventos/ article/view/674/485

Bauer, M. W., \& Gaskell, G. (2015). Pesquisa qualitativa com texto, imagem e som (13 ed.). Vozes.

Bucci, E. (2020). A humanidade encontra sua irrelevância. Estudos Avançados, 34(99), 245-260. https://doi.org/10.1590/s01034014.2020.3499.015

Caprini, F. R., \& Motta, A. B. (2020). O impacto psicológico em familiares cuidadores de crianças e adolescentes com anemia falciforme. Estudos de Psicologia (Campinas), 38, e190168. https://doi.org/10.1590/1982$\underline{0275202138 \mathrm{e} 190168}$

Comparini, A. C. F. M., Ribeiro, D. F., Andrade, A. S., \& Gomes, A. T. (2015). O jogo dramático com mulheres de uma comunidade: revelando potências de desenvolvimento humano e social. Revista Brasileira de Psicodrama (São Paulo), 23(2), 32-41. http://dx.doi.org/10.15329/2318$\underline{0498.20150005}$ 
Creswell, J. W. (2014). Investigação qualitativa \& projeto de pesquisa (S. M. Rosa, Trad.; 3a. ed.). Artmed.

Davel, E. P. B., Oliveira, J. S., \& Ventura, A. C. (2020). Criatividade na ação política. Organizações \& Sociedade, 27(93), 178-181. https://doi.org/10.1590/1984-9270930

Fonseca, J. (2012). Onde está reconhecimento do ele na matriz de identidade? Interseções sobre Lacan e Moreno. Revista Brasileira de Psicodrama, 20(1), 115-134. http://pepsic. bvsalud.org/scielo.php?script=sci_arttext\&pid=S010453932012000100009\&lng=pt\&tlng=pt

Frankl, V. (2006). Man's Search for Meaning [A busca do homem pelo sentido]. Beacon Press.

Garbim, K. A., Almeida, V. O., \& Vitali, M. M. (2020). Psicodrama de grupo e dependência química: trabalhando projetos profissionais e experiências de lazer. Perspectivas em Psicologia, 24(1), 1-20. www.seer.ufu.br/index.php/ perspectivasempsicologia/article/view/57680/30419

Gasques, B. L., Bolsoni, C. L., Milani, R. G., \& Macuch, R. S. (2019, 29 a 30 de Outubro). Introdução teóricometodológica ao psicodrama. In Anais Eletrônico do XI EPCC - Encontro Internacional de Produção Científica ( p. 1-4). Maringá, PR. http://rdu.unicesumar.edu.br/ bitstream/123456789/3758/1/Bruna\%20Lima\%20Gasques. pdf

Gomes, R. (2014). Pesquisa qualitativa em saúde. Instituto Sírio-Libanês de Ensino e Pesquisa. https://iep. hospitalsiriolibanes.org.br/Documents/LatoSensu/ caderno-pesquisa-qualitativa-mestrado-2014.pdf

Gutiérrez-Torres, A. M., \& Buitrago-Velandia, S. J. (2019). Las Habilidades Socio emocionales de los Docentes, herramientas de paz en la escuela [As Habilidades Sociais Emocionais dos Professores, ferramentas para a paz na escola]. Praxis \& Saber, 10(24), 167-192. http://dx.doi org/10.19053/22160159.v10.n25.2019.9819

LaCaille, L. (2013). Theory of Reasoned Action [Teoria da Ação Racional]. In M. D Gellman, \&J. R Turner (Eds.). Encyclopedia of Behavioral Medicine. Springer. http://dx.doi. org/10.1007/978-1-4419-1005-9 1619

Maders, A. M., \& Angelin, R. (2012). Os movimentos feministas e de mulheres e o combate aos conflitos de gênero no Brasil. Prisma Jurídico, 11(1), 13-31. https://www.redalyc. org/articulo.oa?id=93426128002
Myers, G. (2015). Análise da conversação e da fala. In M. W. Bauer, \& G. Gaskell (Orgs). Pesquisa qualitativa com texto, imagem e som: um manual prático (13a ed., pp. 271-292). Vozes.

Querino, L. C., Domingues, M. D., \& Luz, R. C. (2013). A evolução da mulher no mercado de trabalho. E-FACEQ: revista dos discentes da Faculdade Eça de Queirós, 2(2), 1-32. http:// uniesp.edu.br/sites/_biblioteca/revistas/20170427174519. pdf

Ramalho, C. M. R. (2010). Sandplay Psicodramático - Um jogo na interface do psicodrama com a psicologia analítica. Revista Brasileira de Psicodrama, 18(2), 107-117. http://pepsic. bvsalud.org/scielo.php?script=sci_arttext\&pid=S010453932010000200007\&lng=pt\&tlng=pt

Salvani, J., Veronese, M. V., \& Guerin, M. (2017). Identidade de gênero: percursos de resistência no trabalho tido como masculino. Tríade: Revista de Comunicação, Cultura e Mídia 5(10), 162-178. http://periodicos.uniso.br/ojs/index.php/ triade/article/view/3067

Schlickmann, E., \& Pizarro, D. (2013). A evolução da mulher no trabalho: uma abordagem sob a ótica da liderança. Revista Borges: Ciências Sociais Aplicadas em Debate, 3(1), 70-89. http://www.revistaborges.com.br/index.php/borges/ article/viewFile/43/117

Simões, F. I. W., \& Hashimoto, F. (2012). Mulher, mercado de trabalho e as configurações familiares do século XX. Vozes dos Vales, 1(2),1-25. http://hdl.handle.net/11449/126924

Souza, E. S., \& Santos, S. P. (2014). Mulheres no mercado de trabalho: um estudo com estudantes universitários do curso de administração de uma faculdade particular de São Paulo (SP). E-FACEQ: revista discentes da Faculdade Eça de Queirós, 3(3), 1-19. http://uniesp.edu.br/sites/ biblioteca/revistas/20170427174739.pdf

Tao, H. B. (2016). Neurociencias, educación y entorno sociocultural [Neurociências, educação e entorno sociocultural]. Educación y Educadores, 19(3), 395-415. https://www.redalyc.org/pdf/834/83448566005.pdf

Vaz, C. E., \& Alchieri, J. C. (2016). Z-Teste Coletivo e Individual: Técnica de Zulliger ( $3^{\mathrm{a}}$. Ed.). Hogrefe.

Villemor-Amaral, A. E., \& Primi, R. (2012). Zulliger no Sistema Compreensivo - ZSC - forma individual (2a . Ed.). Pearson.

Weber, M. (1964). Economia e Sociedade. Fondo de Cultura Econômica. 